Thorax (1974), 29, 287.

\title{
Epidermolysis bullosa of the oesophagus with oesophageal web formation
}

\author{
R.A. MARSDEN, F. J. SAMBR O OK G OWAR, \\ A. F. M a c D O N A D, and R. A. M A I N \\ Departments of Dermatology, Thoracic Surgery, and Radiology, \\ Aberdeen Royal Infirmary, Aberdeen
}

\begin{abstract}
Marsden, R. A., Sambrook Gowar, F. J., MacDonald, A. F., and Main, R. A. (1974). Thorax, 29, 287-295. Epidermolysis bullosa of the oesophagus with oesophageal web formation. Four members of a family are described with epidermolysis bullosa dystrophica of probable autosomal recessive inheritance. They have shown the typical blistering of the skin and oral mucosa, usually present at birth, which occurs in this uncommon condition. Lesions occur after minor injury and heal slowly with scarring. Abnormalities of the nails and teeth are also present.

Oesophageal mucosal involvement can be a serious feature of this type of epidermolysis bullosa and usually manifests clinically as dysphagia and regurgitation of food and blood; oesophageal stenosis may ensue. Dysphagia was present in all four patients described in this study and regurgitation of an oesophageal cast occurred in one. Severe oesophageal stenosis occurred in two patients and minor narrowing and irregularity was present in the others. Treatment by oesophagoscopy and bouginage was carried out in the two patients with stenosis with some relief of dysphagia.

Oesophageal webs have rarely been reported in epidermolysis bullosa. In all four of our patients a postcricoid web was found. The presence of a smooth tongue in four patients and anaemia in two suggests the co-existence of the Paterson-Brown Kelly syndrome, although alternatively these webs may have resulted from the blistering and scarring process of epidermolysis bullosa.
\end{abstract}

Epidermolysis bullosa dystrophica is an uncommon hereditary disorder in which the skin blisters spontaneously or with injury. Dominant and recessive forms are recognized (Rook, Wilkinson, and Ebling, 1972), the dominant type being commoner and generally less severe.

In the autosomal recessive form (estimated incidence 1 in 300,000 births) extensive lesions are usually present at birth. The blisters are subepidermal and often haemorrhagic. Once they have burst, healing takes place slowly with atrophic scarring. Teeth, hair, and nails may be abnormal (Figs 1 and 2). In severe cases death may occur from infection, or scar formation may result in flexion deformities of limbs and webbing of fingers and toes.

Blistering of the mucous membranes is a feature of this condition. Oral involvement may give rise to buccal contractures and considerable feeding difficulties in infancy and childhood. In the oesophagus similar lesions may progress to stenosis. Oesophageal webs have been infrequently reported in epidermolysis bullosa.

The aim of this study is to present four members of a family with epidermolysis bullosa dystrophica. Two of them were referred to a thoracic surgery unit complaining of dysphagia at a time when the skin disease was so inactive that it was overlooked. Later two other members of the family were investigated when it became known that they also suffered from blistering of the skin and dysphagia. Involvement of the oesophagus in epidermolysis bullosa is discussed with reference to its association with oesophageal web formation.

\section{CASE REPORTS}

The four cases described are the only affected members of a family of eight. The parents and relatives are apparently normal as are the children of cases 3 and 


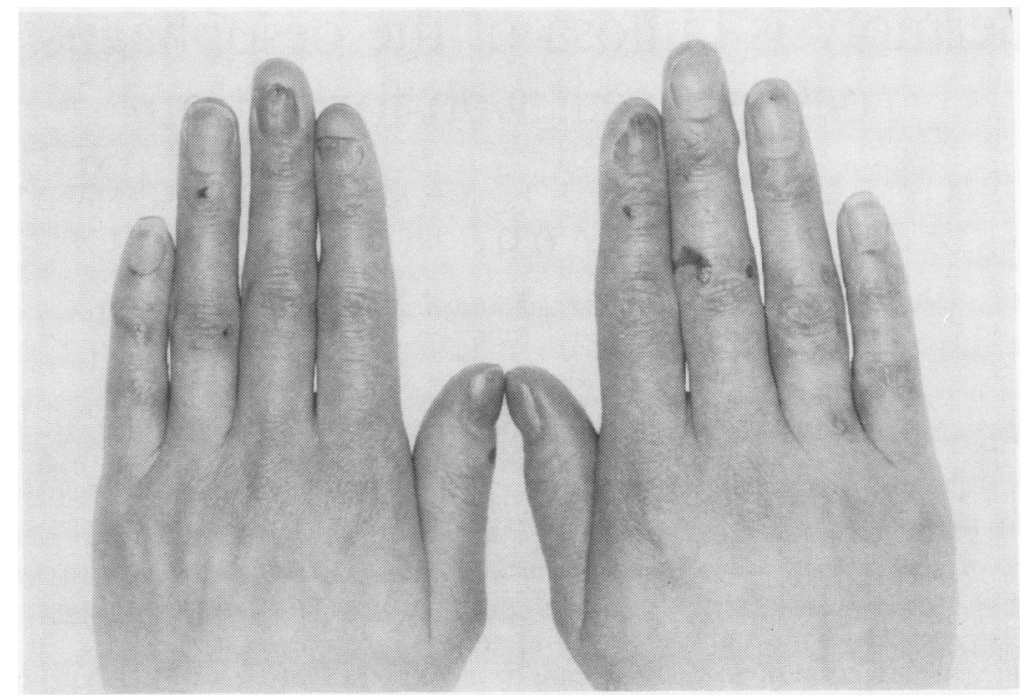

FIG. 1. Case 3. Nail dystrophy and haemorrhagic blisters. The hands of case 1 (not illustrated) are similar but not as severely affected.

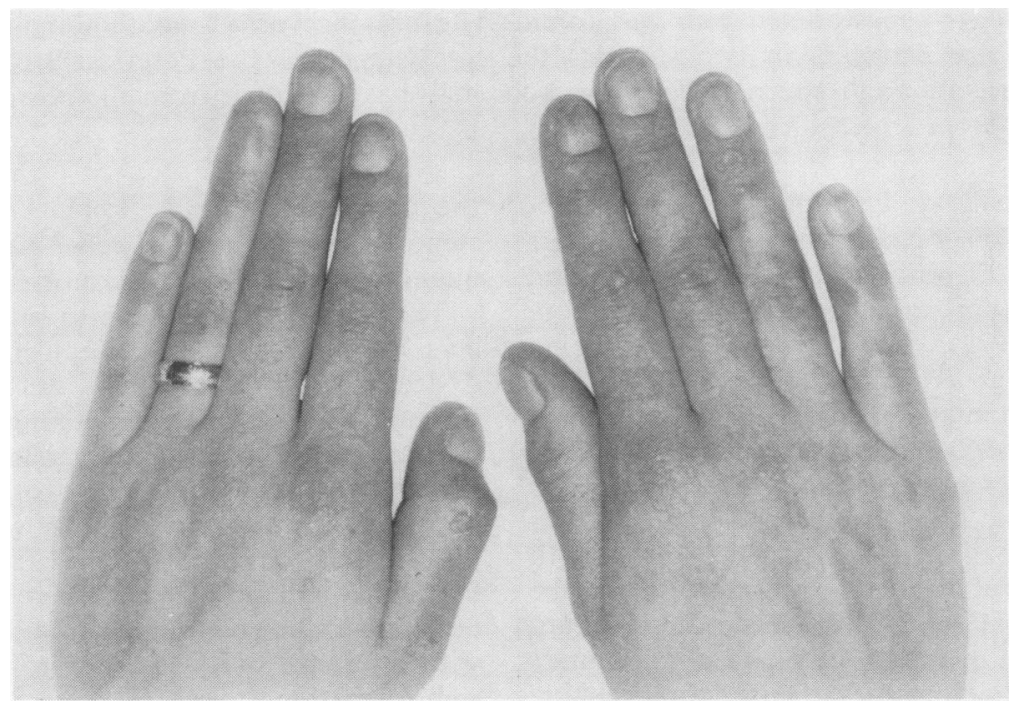

FIG. 2. Case 4. Loss of left ring finger nail and slight scarring of left thumb and right ring finger. The hands of case 2 (not illustrated) show similar mild scarring with normal finger nails. 


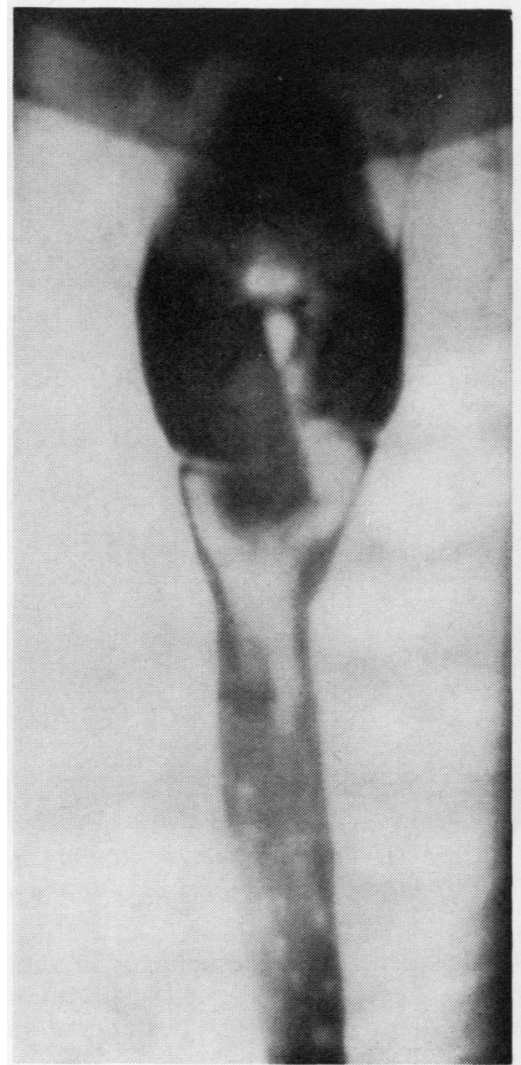

(a)

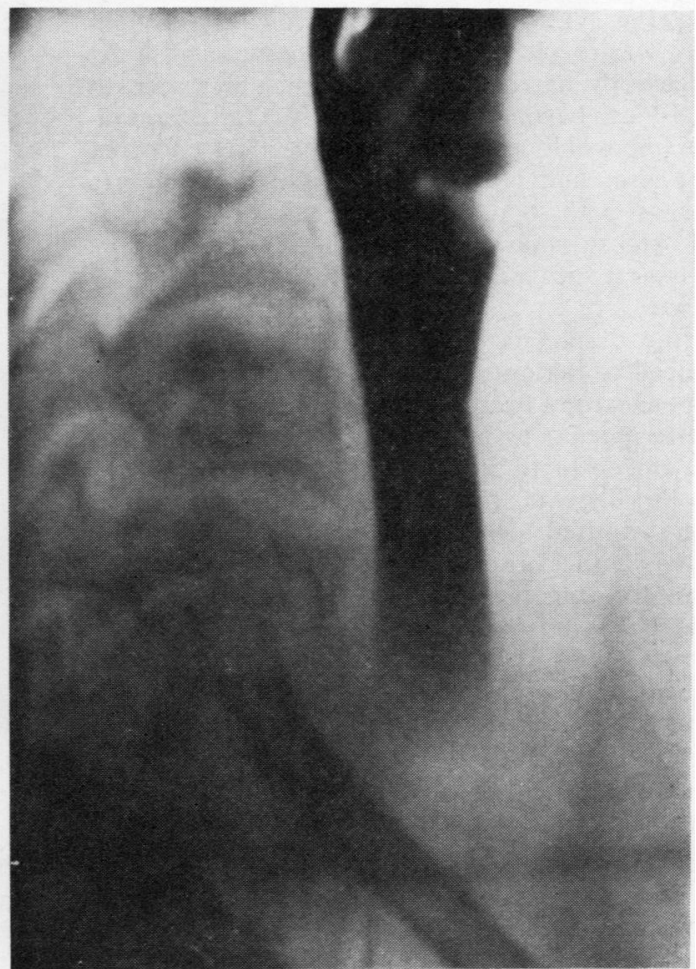

(b)

FIG. 3. Case 1. AP (a) and lateral (b) views. Barium swallow $70 \mathrm{~mm}$ film at 3 frames/sec showing typical anterior cricopharyngeal web.

4. There is no evidence of consanguinity and although the maternal grandmother bore the same surname as our patients her family originated from a different area. The pedigree therefore suggests recessive inheritance.

CASE 1 A.G., a man, aged 21, was born with extensive haemorrhagic blisters on the limbs and trunk. New blisters readily occurred, apparently induced by minor injury. Oral lesions were present but did not impair feeding. Epidermolysis bullosa was diagnosed on clinical and histological findings. At the age of 4 months considerable improvement had occurred and the patient was not seen again until 14 years later.

At this time he attended the Thoracic Surgery Unit of Aberdeen Royal Infirmary with an eight-year history of dysphagia at cricoid level. He occasionally experienced pain in the throat and a retrosternal ache when swallowing solids or hot liquids. No history of skin disorder was given. On examination he appeared well nourished; mouth, tongue, and teeth were normal at this time. Haemoglobin was $12 \cdot 1 \mathrm{~g} / 100 \mathrm{ml}$. Routine barium swallow examination detected no abnormality.

Oesophagoscopy showed a thin posterior mucosal fold in the upper oesophagus 14-15 cm from the upper teeth. Excessive bleeding prevented passage of the instrument through the web, and only partial dilatation with bougies was possible. Thereafter the patient was well for four years until a food particle lodged in the throat, causing local pain, choking, and vomiting of blood. On this occasion the patient admitted that his skin blistered easily in response to knocks and blows. The lesions required on average two months to heal and left scars. Some of his nails were brittle and the right great toe nail had been lost at the age of 5 and had not regrown.

Examination revealed several haemorrhagic tensc blisters on the backs of the hands and fingers with atrophic scars over the knuckles, feet, and shins. Some of the nails were small, transversely narrowed, thickened, and opaque. Advanced dental caries and 
angular stomatitis were noted; the tongue was smooth. Haemoglobin was $12.7 \mathrm{~g} / 100 \mathrm{ml}$.

An upper oesophageal web was visible radiologically (Fig. 3) together with narrowing throughout the entire length of the oesophagus. At oesophagoscopy narrowing of the lumen was seen to extend $2-3 \mathrm{~cm}$ beyond the web but further examination was impossible as considerable bleeding occurred from the thin and congested mucosa. The stricture was dilated with bougies to size 20 (English). A mucosal biopsy showed epithelial replacement by granulation tissue and subepithelial infiltration by lymphocytes.

Soon the dysphagia was worse than ever and he was reduced to taking semisolids. Two more attempts at oesophagoscopy were therefore made. The first caused the mucosa to be lifted off 'like tissue paper' from $20 \mathrm{~cm}$ down to $30 \mathrm{~cm}$ with free bleeding. Subsequent histology of the fragment showed it to be apparently normal oesophageal epithelium. At the next attempt the original web could not be found but a smooth, tapered narrowing was present $7 \mathrm{~cm}$ lower down, and further on there was evidence of acute oesophagitis with circumferential slough covering the inflamed mucosa. A second stricture was located at $27 \mathrm{~cm}$ and dilated 12-20 (English) with bougies.

At the present time the patient has slight dysphagia but eats a normal diet. Occasionally his skin blisters but he is able to work as a joiner.

CASE 2 D.G., a girl, aged 16, was seen shortly after birth with extensive lesions of epidermolysis bullosa dystrophica involving the skin and mouth. The entire skin below the right knee had degloved. From the age of $4 \frac{1}{2}$ months the condition improved and at present considerable trauma is required to blister the skin.

No further specialist care was sought until the age of 15 when the patient developed acute substernal pain with regurgitation of blood after choking on a potato crisp. She recalled that for as long as she could remember she had had difficulty in swallowing meat which seemed to stick at the level of the cricoid. She expressed no concern about her skin, which she considered normal, and the history of previous skin disorder was discovered only later when her relationship to case 1 was established.

On examination her skin was scarred over the fingers, knees, shins, medial malleoli, and the dorsum of the feet. The skin below the right knee was shiny, thin, and paper-like in appearance. The toe nails were small, thickened, and opaque. There were erosions on the buccal mucosa and advanced dental caries was present. The tongue was smooth. Haemoglobin was $11.0 \mathrm{~g} / 100 \mathrm{ml}$.

Barium swallow showed persistent narrowing in the upper third of the oesophagus, due presumably to spasm or fibrosis (Fig. 4). Barium swallow, using $70 \mathrm{~mm}$ film at 3 frames/sec, showed no abnormality

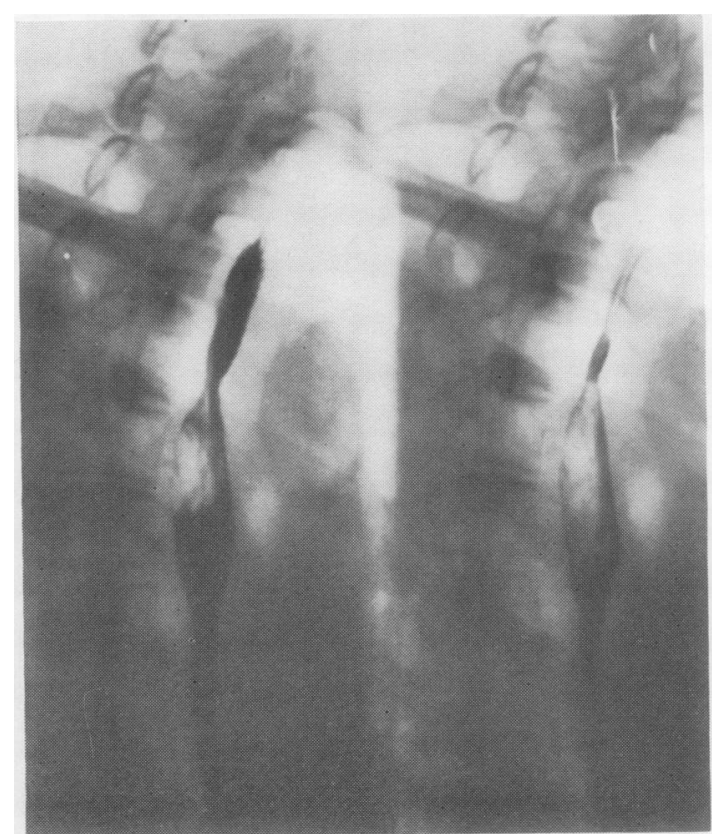

FIG. 4. Case 2. Oblique views showing persistent smooth narrowing in upper third of oesophagus.

in the pharynx or upper oesophagus in the anterior view but the lateral view showed an indentation possibly due to a web or a normal postcricoid impression (Pitman and Fraser, 1965).

Oesophagoscopy revealed a circumferential, diaphragm-like stricture lined with granulation tissue $\overrightarrow{\vec{\sigma}}$ at the oesophageal entrance. After dilating the $\frac{0}{2}$ stricture with bougies the oesophagoscope was $\stackrel{\times}{\times}$ passed through but the lower oesophagus was not $\frac{\sigma}{3}$ visualized owing to bleeding.

Two months later the patient again developed severe $\delta$ retrosternal pain while eating, followed by vomiting of fresh blood. On this occasion her retching pro-을 duced a 'string-like substance, looking like skin, six inches in length' which she removed from the throat with her fingers.

Oesophagoscopy showed acute oesophagitis with oedema and slough at the oesophageal entrance. The previously noted stricture was dilated with bougies? and the oesophagoscope advanced into the lower $\omega$ oesophagus. Similar inflammatory changes were seen in the lowest $5 \mathrm{~cm}$ but there was no narrowing ande the instrument could be passed into the stomach. Her swallowing gradually improved following bouginage? until she was able to take a normal diet. Recently she relapsed and is currently able to swallow only뭄 fluids.

CASE 3 R.E., a woman, aged 28, had had blistering of the palate and tongue at birth which gave rise to 
feeding difficulties. Blistering of the hands, knees, and feet was also present and worsened with crawling and walking. Some improvement occurred after the first year although bullae continued to appear. A total dental clearance was performed at the age of 16 . At the age of 20 she first encountered difficulty in swallowing meat which seemed to lodge at cricoid level. Occasionally she would regurgitate food but was usually able to eat a normal diet. She has two normal children.

Examination of the skin shows typical changes of epidermolysis bullosa dystrophica, most marked on the hands and feet (Fig. 1). Some nails are dystrophic and are shed periodically. Angular stomatitis is present and shallow erosions are seen on the buccal mucosa. The tongue is smooth and the lingual frenum absent.

Barium swallow demonstrates slight residual irregularity in the posterior margin of the upper third of the oesophagus. There is no evidence of narrowing or spasm. Barium swallow using three exposures per second on $70 \mathrm{~mm}$ film shows an anterior web in the upper oesophagus with characteristic transverse translucency on the AP view (Fig. 5).

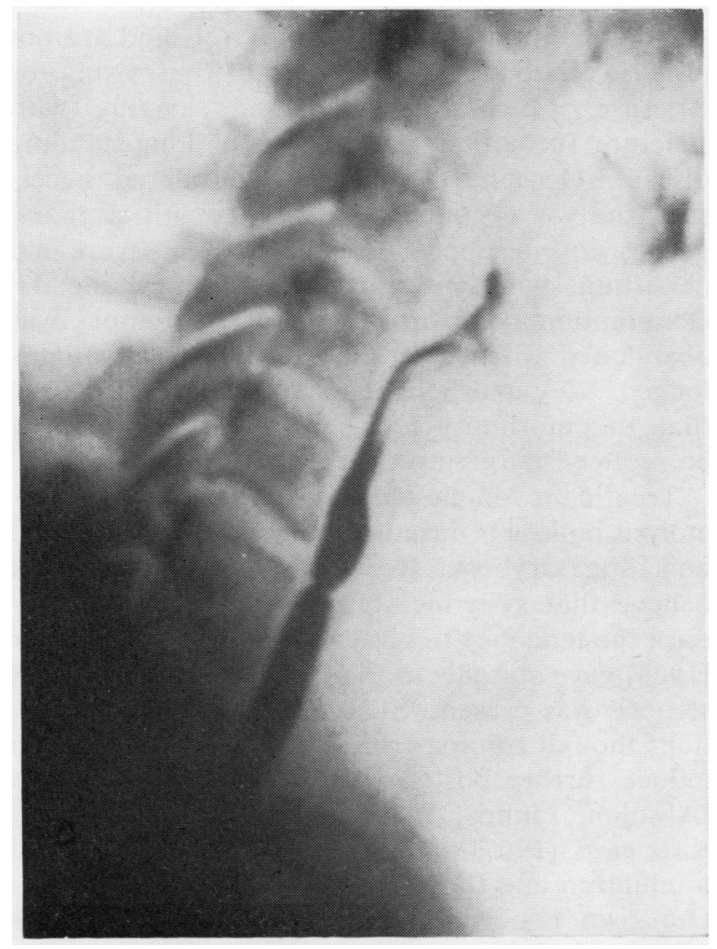

FIG. 5. Case 3. Barium swallow $70 \mathrm{~mm}$ film at 3 frames/sec showing typical anterior cricopharyngeal web.
CASE 4 R.G., a woman, aged 23, was born with the umbilical cord wrapped tightly around her neck. When it was removed, the underlying skin sloughed off completely. Bullae appeared sporadically on pressure areas during early childhood but new lesions have not been noticed for many years. Oral erosions have continued to occur. From the age of 11 the patient avoided eating meat since it tended to stick at the level of the cricoid cartilage. There was frequent regurgitation of food streaked with blood. The patient has one normal infant.

The skin and nails show changes consistent with epidermolysis bullosa dystrophica (Fig. 2). Ragged, haemorrhagic, shallow erosions are present in the mouth. Advanced dental caries is present and the tongue is smooth with restriction of forward protrusion.

Barium swallow shows a persistent irregular narrowing just above the carinal level, indicating spasm of the oesophagus and possibly some fibrotic contraction. Barium swallow using $70 \mathrm{~mm}$ film at 3 frames/sec shows an upper oesophageal web in lateral and AP films (Fig. 6). In the lateral it appears below a probably normal postcricoid impression (Pitman and Fraser, 1965).

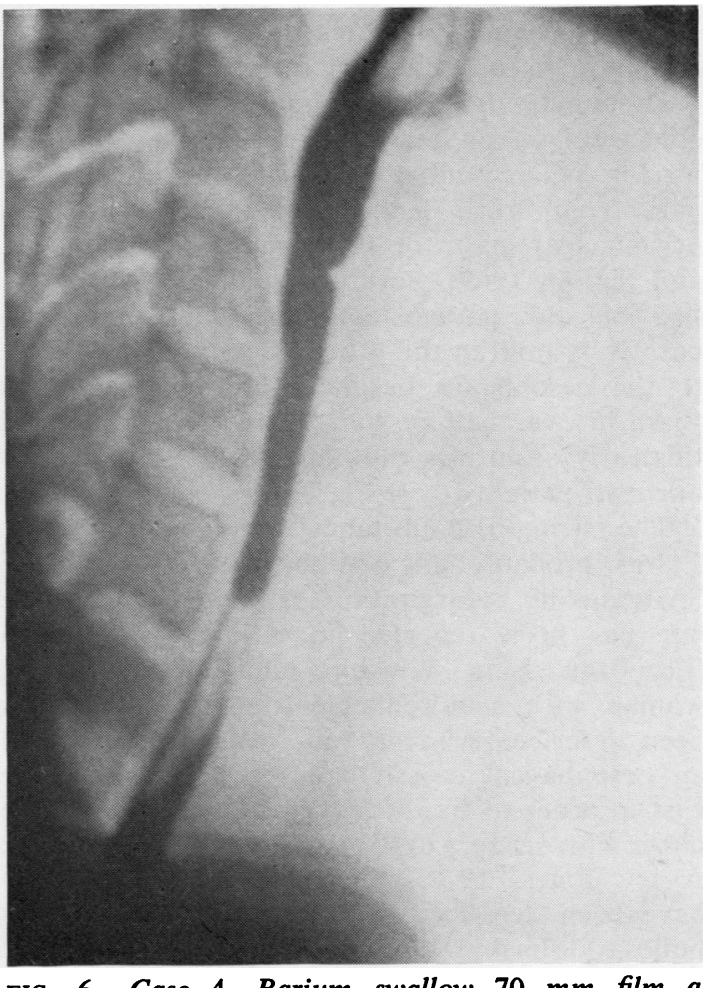

FIG. 6. Case 4. Barium swallow $70 \mathrm{~mm}$ film at 3 frames/sec showing anterior cricopharyngeal web. 


\section{DISCUSSION}

Oesophageal involvement is recognized in the recessive form of epidermolysis bullosa dystrophica. Bergenholtz, Olsson, Arwill, and Lundström (1965) and Nix and Christianson (1965) reviewed a total of 28 cases occurring in the literature from 1899 to 1962 and added four cases of their own. Schild, Vander Aarde, and Holinger (1972) listed 13 further cases and added two more. Another eight cases are described by Moynahan (1963), Wey and Schnyder (1964), and Schuman and Arciniegas (1972).

Blistering in epidermolysis bullosa is produced by minor injury but the essential mechanism is not known. Presumably trauma from hot or rough foods causes separation of the oesophageal epithelium from the lamina propria. Since the upper third of the oesophagus is the narrowest and least distensible, this might account for it being the most commonly affected segment. The distal third is the next most commonly involved, possibly because it is subject to both reflux gastric juice and pulsations of the heart and aorta (Hadley and MacDonald, 1960; Bergenholtz et al., 1965). Repeated blistering and healing probably results in fibrosis and stricture formation.

Dysphagia is the commonest symptom of epidermolysis bullosa of the oesophagus and is usually severe and disabling. It may be due to pain from areas denuded of mucosa, or from oesophageal spasm or stricture (Dupree, Hodges, and Simon, 1969). Severe dysphagia occurred in two of our patients but has remained comparatively mild in the others. Symptoms referable to the oesophagus began before the age of 14 years in over half of the recorded 55 cases, and this early onset of symptoms is well illustrated by our own patients.

The 'string-like substance' regurgitated by case 2 was probably an oesophageal mucosal cast. Spontaneous regurgitation of such casts is rare but has been reported in bullous pemphigoid (Foroozan, Enta, Winship, and Trier, 1967). A woman with acquired epidermolysis bullosa has been described who on four occasions produced an oesophageal cast. Once she bit through the cast in order to free it from her throat and twice cut it with scissors (Willcox, 1949; Johnson, 1967; Avery Jones, 1972). Such casts appear not to have been described in hereditary epidermolysis bullosa (Johnson, 1967).

Radiological examination is usually helpful when oesophageal involvement is suspected. A smooth tapered narrowing or stricture $2-4 \mathrm{~cm}$ in length is often seen. Occasionally more diffuse $-\overrightarrow{0}$ narrowing or multiple strictures are present. 흘 Diminished peristalsis, prestenotic dilatation or $\overline{\bar{c}}$ oesophageal spasm are common, and actualब ulceration of the mucosa was shown in one patient by Becker and Swinyard (1968). Radiologicales evidence of narrowing and irregularity of the $\vec{O}$ upper third of the oesophagus was present in all $\overrightarrow{\vec{\omega}}$ our four patients. The dysphagia experienced by cases 3 and 4 was never severe enough for them $\vec{x}$ to seek medical assistance. Perhaps if all patients with epidermolysis bullosa were subjected to $a_{\omega}^{c}$ routine barium swallow examination then oeso-i phageal involvement might be found to be more common than has hitherto been suspected.

Oesophagoscopy is particularly difficult and hazardous in this condition. Microstomia, oeso- $\vec{z}$ phageal spasm, or diffuse narrowing of the entire oesophagus may prevent passage of the instru- $\vec{\varphi}$ ment. Oesophageal lesions may be produced or $\stackrel{-}{\perp}$ extended as the instrument advances and lengths of oesophageal mucosa may be lifted off (Schildo et al., 1972). Vesicles, bullae or an inflamed mucosa with granulation tissue are of ten seen: these changes may occur at all levels and are not $\frac{0}{D}$ always related to a segment of narrowing or $\stackrel{\varrho}{\Rightarrow}$ stricture. Mucosal atrophy and scarring with stricture formation is a feature of long-standing disease. Oesophagoscopy was considered necessary in two of our patients since initial radiographs did not appear to explain their severe and persisting symptoms. Profuse bleeding made the examination difficult and one attempt was. abandoned when a $10 \mathrm{~cm}$ mucosal cast was dis-3.3. lodged. Wey and Schnyder (1964) have suggested that the morbidity from instrumentation might be reduced by giving concomitant prednisolone.

Treatment of oesophageal lesions in epidermolysis bullosa is unsatisfactory. Moynahan (1963) and Katz, Gryboski, Rosenbaum, and Spiro (1967) believe that systemic steroids in high dosage re- $\sigma$ duce the tendency to blistering. Wey and Schnyder N (1964) gave steroids to their patients if even slight స్ట stenosis was present. Stenoses may require dilata-o tion, though trauma from bouginage may in turn induce further blistering and stricture formation (Absolon, Finney, Waddill, and Hatchett, 1969). $\stackrel{\oplus}{\rightleftharpoons}$ Katz et al. (1967) suggest that it should be avoided in children and those with active bulla formation. Our own two cases treated in this manner ob- $\mathbb{\mathbb { D }}$ tained relief from their symptoms but improve- $\overrightarrow{\mathbb{Q}}$ ment was not always immediate or long lasting.

Further surgical treatment seemed limited to

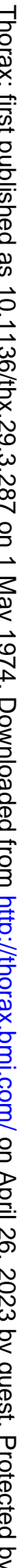


permanent gastrostomy until Absolon et al. (1969) successfully performed an oesophageal bypass with a retrosternal colonic transplant in two children. The postoperative period was relatively free from complications and at present both patients are well and swallow normally (Absolon, 1973; Waddill, 1973, personal communications). Another satisfactory result from the operation has been described by Schuman and Arciniegas (1972).

Haemorrhage and regurgitation of blood commonly complicates epidermolysis bullosa of the oesophagus and occurred, with varying degrees of severity, in three of the cases studied. Food may lodge above a stricture and require removal by oesophagoscopy (Nix and Christianson, 1965). Death may result from malnutrition. Nix and Christianson (1965) describe a young man with multiple strictures who died following spontaneous rupture of the lower oesophagus. Cases associated with oesophageal carcinoma (Sonneck and Häntzschel, 1961), hiatus hernia (Alpert, 1957), and pulmonary fibrosis (Sadler, 1955) are recorded.

Oesophageal webs have rarely been reported in epidermolysis bullosa. Margulis and Burhenne (1967) state that oesophageal webs complicate epidermolysis bullosa and quote a single patient described by Moynahan (1963) of a 14-year-old boy with a flap-like scar in the pharynx. Another case is recorded by Wey and Schnyder (1964). Sonneck and Häntzschel (1961) describe a 38year-old woman with an upper oesophageal mucosal fold and epidermolysis bullosa; although she was anaemic no reference is made to the Paterson-Brown Kelly syndrome.

In the four patients studied, an upper oesophageal web was found. Routine barium swallow examination failed to demonstrate a web in cases 1 and 2 although one was detected later at oesophagoscopy. Rapid films were required to show webs in the other two patients. It is well known in diagnostic radiology that the more assiduous the search for oesophageal webs, the more are found. Therefore they may be commoner in epidermolysis bullosa than the few existing case reports would seem to indicate. It is important to differentiate radiologically true webs from transient, incidental indentations on the anterior cricopharyngeal wall. The webs discovered in our patients were single transverse structures of the type seen in the Paterson-Brown Kelly syndrome. In case 1 the web was seen to be a simple fold of mucosa whereas in case 2 it consisted mainly of granulation tissue. Both webs were adjacent to areas affected by epidermolysis bullosa.

Previous reports of webs in epidermolysis bullosa have suggested that they are secondary to blistering and scarring of the oesophageal mucosa. Benedict and Lever (1952) feel that a similar process could account for webs found in the acquired blistering condition-benign mucous membrane pemphigoid. They describe several patients with single transverse webs and one who had unusual multiple vertical and oblique adhesions dividing the oesophageal lumen into two channels.

In our own cases, however, the presence of webbing might indicate the co-existence of the Paterson-Brown Kelly syndrome. Dysphagia is a constant feature of the syndrome and a postcricoid web the commonest associated radiological abnormality. Angular stomatitis, glossitis, complete loss of the teeth in early life, and hypochromic anaemia are other abnormalities commonly, but not invariably, found, and their occurrence in the cases studied is summarized in the Table.

It is widely believed that all the features of the Paterson-Brown Kelly syndrome, including oesophageal webbing and dysphagia, are secondary to a deficiency of iron (Witts, 1931; McGibbon, 1935; Waldenstrom and Kjellberg, 1939; Chisholm, Ardran, Callender, and Wright, 1971) or some other nutritional factor such as riboflavin, pyridoxine or vitamin B12 (Horwitt et al., 1949; Jacobs and Kilpatrick, 1964; Jacobs and Cavill, 1968). Conversely, it has been suggested that dysphagia itself produces dietary impairment leading to the tissue changes of the Paterson-Brown Kelly syndrome (Vinson, 1922; Jones, 1961; Elwood, Jacobs, Pitman, and Entwistle, 1964). This latter sequence of events may have occurred in our patients, possibly aggravated by blood loss.

Finally, it should be noted that the extent of the skin involvement has varied considerably in previously reported patients with epidermolysis bullosa of the oesophagus. Most of them, particularly those presenting in childhood, have had extensive blistering of the skin which in some cases has given rise to grotesque flexion deformities of the limbs and fusion of the fingers. In others, skin involvement has been less severe with apparent improvement in adult life. Our own patients, however, are remarkable in that since infancy the skin disease has been relatively inconspicuous. Because of this, the skin changes of case 1 were overlooked when he presented with the more immediate problem of dysphagia. 


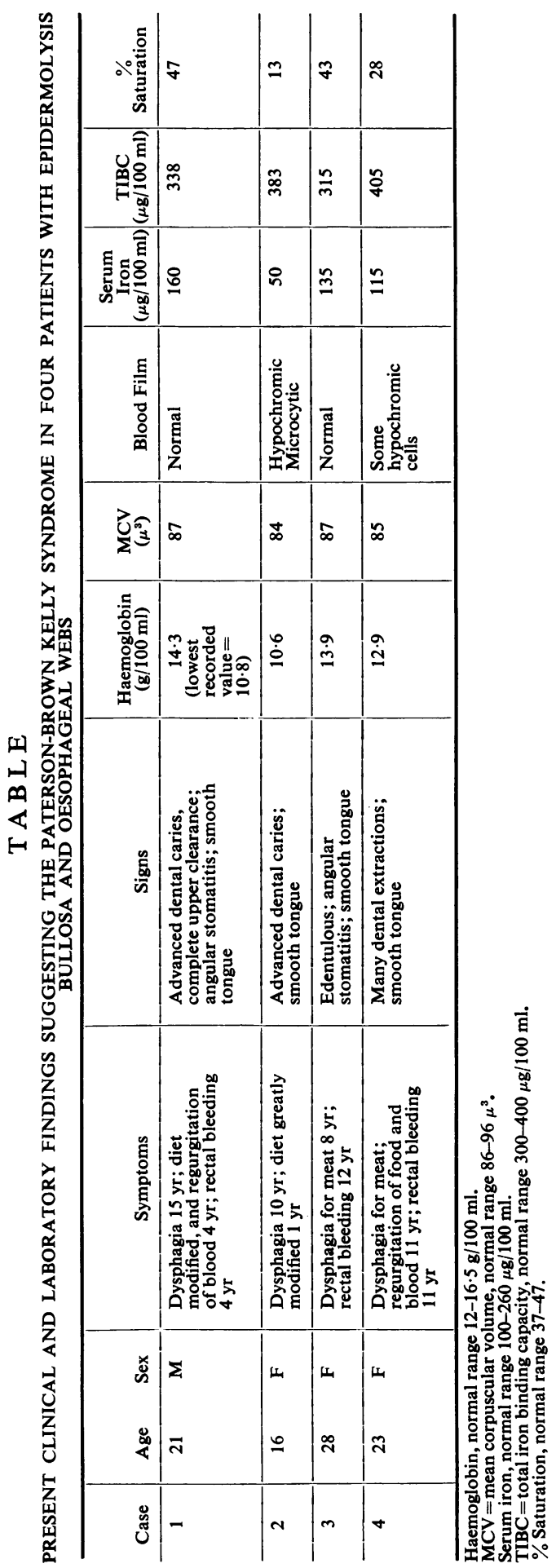


The authors suggest that skin and nails be carefully inspected in all cases of dysphagia.

We are grateful to Mr. G. Martin of the Department of German, Aberdeen University and to Dr. A. W. Johnston of Aberdeen Royal Infirmary, for their assistance.

\section{REFERENCES}

Absolon, K. B. (1973). Personal communication.

—, Finney, L. A., Waddill, G. M., and Hatchett, C. (1969). Esophageal reconstruction-colon transplant-in two brothers with epidermolysis bullosa. Surgery, 65, 832 .

Alpert, M. (1957). Roentgen manifestations of epidermolysis bullosa. American Journal of Roentgenology, 78, 66.

Avery Jones, Francis (1972). The skin and the gut. Modern Geriatrics, 2, 186.

Becker, M. H. and Swinyard, C. A. (1968). Epidermolysis bullosa dystrophica in children. Radiology, 90, 124.

Benedict, E. B. and Lever, W. F. (1952). Stenosis of the esophagus in benign mucous membrane pemphigus. Annals of Otology, Rhinology and Larynology, 61, 1120.

Bergenholtz, A., Olsson, O., Arwill, T., and Lundström, N. R. (1965). Oesophageal changes in epidermolysis bullosa hereditaria dystrophica. Practica Oto-rhino-laryngologica, 27, 219.

Chisholm, M., Ardran, G. M., Callender, S. T., and Wright, R. (1971). A follow-up study of patients with post-cricoid webs. Quarterly Journal of Medicine, 40, 409.

Dupree, E., Hodges, F., and Simon, J. L. (1969). Epidermolysis bullosa of the esophagus. American Journal of Diseases of Children, 117, 349.

Elwood, P. C., Jacobs, A., Pitman, R. G., and Entwistle, C. C. (1964). Epidemiology of the Paterson-Kelly syndrome. Lancet, 2, 716.

Foroozan, P., Enta, T., Winship, D. H., and Trier, J. S. (1967). Loss and regeneration of the esophageal mucosa in pemphigoid. Gastroenterology, 52, 548 .

Hadley, M. and MacDonald, A. F. (1960). Case report of epidermolysis bullosa. British Journal of Radiology, 33, 646.

Horwitt, M. K., Hills, O. W., Harvey, C. C., Liebert, E., and Steinburg, D. L. (1949). Effects of dietary depletion of riboflavin. Journal of Nutrition, 39, 357.

Jacobs, A. and Cavill, I. A. J. (1968). Pyridoxine and riboflavin status in the Paterson-Kelly syndrome. British Journal of Haematology, 14, 153.

— and Kilpatrick, G. S. (1964). The Paterson-Kelly syndrome. British Medical Journal, 2, 79.

Johnson, M. L. (1967). Epidermolysis bullosa acquisita with oesophageal casts. Proceedings of the Royal Society of Medicine, 60, 1272.
Jones, R. F. McN. (1961). The Paterson-Brown Kelly syndrome; its relationship to iron deficiency and postcricoid carcinoma. Journal of Laryngology and Otology, 75, 529.

Katz, J., Gryboski, J. D., Rosenbaum, H. M., and Spiro, H. M. (1967). Dysphagia in children with epidermolysis bullosa. Gastroenterology, 52, 259.

Margulis, A. R. and Burhenne, H. J. (1967). Alimentary Tract Roentgenology. C. V. Mosby, Saint Louis.

McGibbon, J. (1935). The oesophageal lesions encountered in cases of dysphagia with anaemia. Journal of Laryngology and Otology, 50, 329.

Moynahan, E. J. (1963). Oral and pharyngeal manifestations of skin disease. Epidermolysis bullosa affecting the buccal and pharyngeal mucosae. Proceedings of the Royal Society of Medicine, 56, 885 .

Nix, T. E. and Christianson, H. B. (1965). Epidermolysis bullosa of the esophagus. Southern Medical Journal, 58, 612.

Pitman, R. G. and Fraser, G. M. (1965). The postcricoid impression on the oesophagus. Clinical Radiology, 16, 34.

Rook, A., Wilkinson, D. S., and Ebling, F. J. G. (1972). Textbook of Dermatology, 2nd edition. Blackwell Scientific Publications, Oxford.

Sadler, R. L. (1955). Dysphagia pneumonitis following epidermolysis bullosa. British Journal of Tuberculosis and Diseases of the Chest, 49, 142.

Schild, J. A., Vander Aarde, S. B., and Holinger, P. H. (1972). Esophageal stricture associated with epidermolysis bullosa dystrophica. Laryngoscope, 82, 510.

Schuman, B. M. and Arciniegas, E. (1972). The management of esophageal complications of epidermolysis bullosa. American Journal of Digestive Diseases, 17, 875.

Sonneck, H. J. and Häntzschel, K. (1961). Über einen Fall von Epidermolysis bullosa dystrophica mit Oesophagusstenose und Kardiacarcinom. Hautarzt, 12, 124.

Vinson, P. P. (1922). Hysterical dysphagia. Minnesota Medicine, 5, 107.

Waddill, G. M. (1973). Personal communication.

Waldenstrom, J. and Kjellberg, S. R. (1939). Roentgenological diagnosis of sideropenic dysphagia. Acta Radiologica, 20, 618.

Wey, W. and Schnyder, U. W. (1964). Über Ösophagusstenosen bei Epidermolysis bullosa hereditaria und ihre Behandlung, Dermatologica, 128, 173.

Willcox, J. M. (1949). Simple oesophageal cast. Lancet, 2, 417.

Witts, L. J. (1931). The syndrome of glossitis, dysphagia and anaemia. Guy's Hospital Reports, 81, 193.

Requests for reprints to: R. A. Marsden, M.R.C.P., Department of Dermatology, Aberdeen Royal Infirmary, Forest Hill, Aberdeen, AB9 22B. 